\title{
World Health Assembly Resolution 69.9 Calls for an End to Unethical Marketing of "Baby Foods"
}

Journal of Human Lactation

2018, Vol. 34(2) 272-275

(C) The Author(s) 2018

Reprints and permissions:

sagepub.com/journalsPermissions.nav

DOI: 10.1 I77/08903344|8754783

journals.sagepub.com/home/jhl

(\$SAGE

\section{Melissa Ann Theurich, MPH $^{\prime}$}

\section{Keywords}

breastfeeding, complementary feeding, International Code of Marketing of Breast-milk Substitutes, policy analysis

\section{Background}

The World Health Organization (WHO) recommends exclusive breastfeeding for the first 6 months of life with continued breastfeeding up to 2 years of age and beyond (WHO, 2017a). The International Code of Marketing of Breast-milk Substitutes and subsequent World Health Assembly (WHA) Resolutions (the International Code) make up a global set of recommendations that was first published by the WHO in 1981 and that regulates the marketing of human milk substitutes, feeding bottles, and teats (WHO, 2017b). Since that time, a number of resolutions have been passed to expand the scope of the International Code.

Following reports of the inappropriate promotion of "toddler milks" and commercial complementary foods (CCF), commonly known as "industrial baby foods," in several countries, WHA Resolution 63.23 was adopted in 2010, recognizing specific marketing practices undermining progress in infant and young child feeding ("WHA63.14 Marketing of food and non-alcoholic beverages to children," 2010). Inappropriate promotion of CCF and toddler milks, for example, through food labels that do not provide adequate or complete messaging on exclusive and continued breastfeeding, has been reported in both wealthy and resource-poor countries (Pereira et al., 2016; Smith \& Blake, 2013).

WHA Resolution 69.9 was adopted in 2016 with the aim to ensure that families receive clear and accurate information on infant and young child feeding and to prevent obesity and other noncommunicable diseases through promotion of healthy diets in infancy and early childhood (WHO, 2016a). The resolution aims to achieve these important objectives through ending the inappropriate promotion of commercial nutrition products that are advertised in ways that aim to replace human milk in the diets of infants and young children (WHO, 2016a). Commercial nutrition products now covered under the International Code include infant formulas, "follow-up" or "follow-on" infant formulas, bottles, teats, bottlefed complementary foods (WHO, 2013a), "toddler milks" or "growing-up milks," CCF, and beverages marketed for infants and young children up to 36 months of age (WHO, 2016a). In addition, commercial nutrition products should meet national and global standards for nutrient composition, safety, and quality (WHO, 2016b).

\section{How Does WHA Resolution 69.9 Protect Exclusive Breastfeeding?}

Food labels in many countries advertise CCF from 4 months of age or fail to advise a recommended age at all (Sweet et al., 2016). The new resolution aims to end advertisements for products that replace human milk and promote solid foods to young infants too early. Similar to CCF, beverages including water should never be marketed for infants younger than 6 months of age.

WHA Resolution 69.9 protects exclusive breastfeeding during the first 6 months of life and aims to end inappropriate advertisements that

- promote CCF as suitable for infants younger than 6 months of age;

- promote bottles and teats as a method for feeding solid foods;

- portray CCF as equivalent, superior, or a good substitute for human milk; and

- cross-promote infant formula (WHO, 2013b).

Cross-promotion means using packaging designs, color schemes, product names, slogans, or mascots that are used for infant formulas on other commercial nutrition products (WHO, 2016b). For example, a company producing both infant

'Department for Metabolic and Nutritional Medicine, Dr. von Hauner Children's Hospital, Ludwig-Maximilians-University of Munich, Munich, Bavaria, Germany

Date submitted: November 28, 2016; Date accepted: January 3, 2018.

Corresponding Author:

Melissa Ann Theurich, MPH, Ludwig-Maximilians-University of Munich, Dr. von Hauner Children's Hospital, Lindwurmstrasse 4, 80337, Munich, Germany.

Email: melissa@theurichconsulting.com 
formula and CCF should not use the same mascot on both food product labels. This provision inherently protects exclusive breastfeeding during the first 6 months of life as well as continued breastfeeding during the complementary feeding period.

\section{How Does WHA Resolution 69.9 Protect Continued Breastfeeding?}

Not only does the new resolution aim to end advertisements that displace human milk in younger infants, it also aims to end advertisements that would displace human milk in the diet of older infants. Although solid foods are a necessary part of the infant diet during the complementary feeding period, they may also be considered human milk substitutes when inappropriately advertised to replace, rather than complement, human milk. WHA Resolution 69.9 protects continued breastfeeding throughout the complementary feeding period, through ending advertisements that recommend serving sizes that are too large for fully breastfed infants (WHO, 2013b).

Recommendations from food manufacturers for portion sizes that are too large encourage CCF intakes that exceed the recommended daily energy intakes from complementary foods. Large portion sizes are problematic because they displace human milk in older breastfed infants.

These types of marketing practices are concerning because they give parents and caregivers unrealistic expectations of the amount of foods that young infants are able to eat, thereby encouraging overfeeding. Ensuring that food labels recommend appropriate portion sizes for infants therefore protects continued breastfeeding, while promoting optimal complementary feeding practices.

\section{How Does WHA Resolution 69.9 Promote Optimal Complementary Feeding?}

The new resolution recognizes the need to promote optimal complementary feeding practices for infants and young children. Optimal complementary feeding means dietary practices that are in line with the WHO and Food and Agriculture Organization of the United Nations dietary guidelines as well as national dietary and food safety guidelines (WHO, 2013b, 2016a).

A number of $\mathrm{CCF}$ on the global market were found to be high in added sugars or otherwise nutritionally inappropriate (Maalouf et al., 2017; Walker \& Goran, 2015). The new resolution aims to end commercial promotion of CCF with low nutritional quality, specifically products that (a) contribute high saturated fat, trans fats, added sugars, and excessive sodium to the diet and (b) do not provide adequate vitamins and minerals to the diet (WHO, 2013b).

It is important to note that WHA Resolution 69.9 guides issues only around marketing of CCF. It does not establish independent nutritional content specifications for commercial nutrition products. Nutritional quality of CCF should be enforced according to applicable local nutrition directives or global directives where local directives are not in place. For example, in the European Union, the current European Directive specifies that the sodium content of processed infant cereals should not exceed $100 \mathrm{mg} / 100 \mathrm{kcal}$ (Commission of the European Communities, 2006). Therefore, commercial cereals with sodium contents that exceed this level and that are commercially promoted for infants and children younger than 36 months would be in violation of the European Directive and the International Code, where both have been adopted.

Furthermore, WHA Resolution 69.9 states that health claims on CCF should not be allowed for CCF unless the claims are specifically approved by international or national food authorities (WHO, 2013b). In keeping with the Global Strategy for Infant and Young Child Feeding, responsible advertising for industrial baby foods should not exclusively promote processed products or undermine traditional or homemade foods (WHO, 2013b). Rather, advertisements should encourage complementary feeding with local foods from a large variety of food groups (WHO, 2013b).

\section{How Does WHA Resolution 69.9 Promote Optimal Nutrition for Preschool-Age Children?}

Novel commercial nutrition products targeting young children, like toddler meals and toddler milks, prompted necessary changes to expand the age range of the International Code. Previously, the International Code covered products until the age of 24 months ( 2 years), but the new resolution expands the International Code to include children up to 36 months ( 3 years) of age.

The resolution protects sustained breastfeeding during the preschool years while ensuring the appropriate marketing of commercial nutrition products for preschool-age children. Despite the expanded age range, the International Code still includes only commercial nutrition products that are marketed for infants and young children. This makes the International Code by itself quite limited in addressing nutrition issues related to other types of foods. According to several reports from lowand middle-income countries in Asia, Latin America, and Africa, commercial snack foods and sugary beverages that are not explicitly marketed for infants and young children are, nevertheless, commonly fed to them (Huffman, Piwoz, Vosti, \& Dewey, 2014; Pries et al., 2016). This is of concern in all countries but is particularly relevant in low- and middle-income countries and in populations with a "double burden of malnutrition," a public health phenomenon whereby both chronic undernutrition and obesity are present in a given population (Huffman et al., 2014).

With a view to childhood obesity risk, the inclusion of young children until 36 months was important for linking the International Code with other international nutrition policies that promote healthy nutrition practices in childhood. These include international policies from the WHO that aim to mitigate unethical marketing of food and beverages to older children and international initiatives to end childhood obesity ("WHA63.14 Marketing of food and non-alcoholic beverages to children," 2010; WHO, 2016c). 


\section{Recommendations for Healthcare Professionals}

A recent study showed that one common reason that parents in the United States prematurely introduced solid foods to their infants is that they were instructed to do so by a healthcare professional (Clayton, Li, Perrine, \& Scanlon, 2013). A report from the Philippines stated that advertising messages are reaching vulnerable, economically disadvantaged sectors of the population and that families are significantly more likely to formula feed if exposed to advertising or if advised to formula feed by a physician (Sobel et al., 2011).

Healthcare professionals should be informed and cognizant of aggressive marketing and promotion tactics used to deceive, exaggerate, confuse, or manipulate both themselves and their patients to practice nutrition behaviors that may be harmful to the health of infants and young children. It is also the responsibility of healthcare providers to recognize and refuse offers with inherent conflicts of interest. Donations of commercial nutrition products are considered a type of marketing; solicitation or acceptance by healthcare professionals, institutions, or associations violate the International Code (WHO, 2016a). Sponsorship of scientific or professional meetings and endorsement of professional activities by companies producing commercial nutrition products covered under the scope of the International Code are no longer permitted and should be systematically refused (WHO, 2016a).

\section{Recommendations for Monitoring and Implementation of the International Code}

Key recommendations for monitoring and implementation of the International Code are to (a) employ public awareness strategies, (b) increase political advocacy for the International Code, and (c) conduct scientific research. Reports of CCF and toddler milks that are marketed in violation of the International Code have been published from Australia, Cambodia, Indonesia, Myanmar, Nepal, Senegal, South Africa, Tanzania, Thailand, Vietnam, and Zambia (Feeley et al., 2016; Funduluka et al., 2017; Pereira et al., 2016; Smith \& Blake, 2013; Sweet, Jerling, \& Van Graan, 2013; Sweet et al., 2016; Vinje et al., 2017) and have been reported in humanitarian emergencies (Hipgrave, Assefa, Winoto, \& Sukotjo, 2012; Theurich \& Grote, 2017).

Public awareness is a strong tool for changing marketing practices that are damaging to public health. Monitoring of compliance with the International Code has historically not been institutionalized or regularly implemented (Forsyth, 2013; Lutter, 2013). Therefore, it seems necessary to innovate external monitoring like public awareness strategies. For instance, following public controversy over high sugar contents of CCF, the European Parliament voted to review the levels of added sugars allowed (Watson, 2016). The controversy decreased real sales volumes of sweetened foods like rusks and juices in the United Kingdom (Euromonitor International, 2016).
To date, only 39 of 194 countries have enacted legislation that covers all of the provisions of the International Code (WHO, 2017c), and in some countries, substantial barriers like trade agreements for the reduction of "barriers to trade and investment" exist (WHO, United Nations Children's Fund, \& International Baby Food Action Network, 2016). During the drafting of WHA Resolution 69.9, there was substantial opposition from the United States, New Zealand, and the European Union, which have extensive infant food manufacturing capacities (Sterken, 2016). Therefore, advocacy work is still needed at political levels for full adoption of the International Code.

Finally, more scientific studies are needed with regard to Resolution 69.9 and the social determinants of purchasing behaviors of vulnerable groups, including how marketing targets or influences vulnerable groups in different world regions.

\section{Conclusion}

Prior to 2016, there was a gap in international nutrition policy protecting infants, young children, and preschoolers from unethical marketing of commercial nutrition products. The International Code protects exclusive and continued breastfeeding and promotes optimal complementary feeding and optimal nutrition for preschool-age children. WHA Resolution 69.9 ensures that families receive clear and accurate information on infant and young child feeding, contributing to prevention of obesity and noncommunicable diseases. Key recommendations include more research, political advocacy, and increasing public awareness.

\section{ORCID iD}

Melissa Ann Theurich (D) https://orcid.org/0000-0001-8928-9004

\section{References}

Clayton, H. B., Li, R., Perrine, C. G., \& Scanlon, K. S. (2013). Prevalence and reasons for introducing infants early to solid foods: Variations by milk feeding type. Pediatrics, 131(4), e1108-e1114. doi:10.1542/peds.2012-2265

Commission of the European Communities. (2006). Commission directive 2006/125/EC of 5 December 2006 on processed cerealbased foods and baby foods for infants and young children. Offical Journal of the European Union. L339/16. Retrieved from http://eur-lex.europa.eu/legal-content/EN/TXT/HTML/? uri=CELEX:32006L0125\&from $=\mathrm{EN}$.

Euromonitor International. (2016). Baby food in the United Kingdom. Retrieved from http://www.euromonitor.com/babyfood-in-the-united-kingdom/report

Feeley, A. B., Ndeye Coly, A., Sy Gueye, N. Y., Diop, E. I., Pries, A. M., Champeny, M., . . Huffman, S. L. (2016). Promotion and consumption of commercially produced foods among children: Situation analysis in an urban setting in Senegal. Maternal \& Child Nutrition, 12(Suppl. 2), 64-76. doi:10.1111/mcn.12304

Forsyth, S. (2013). Non-compliance with the International Code of Marketing of Breast Milk Substitutes is not confined to the infant formula industry. Journal of Public Health, 35(2), 185190. doi:10.1093/pubmed/fds084 
Funduluka, P., Bosomprah, S., Chilengi, R., Mugode, R. H., Bwembya, P. A., \& Mudenda, B. (2017). Marketing of breastmilk substitutes in Zambia: Evaluation of compliance to the international regulatory code. Journal of Public Health. Advance online publication. doi:10.1093/pubmed/fdx023

Hipgrave, D. B., Assefa, F., Winoto, A., \& Sukotjo, S. (2012). Donated breast milk substitutes and incidence of diarrhoea among infants and young children after the May 2006 earthquake in Yogyakarta and Central Java. Public Health Nutrition, 15(2), 307-315. doi:10.1017/s1368980010003423

Huffman, S. L., Piwoz, E. G., Vosti, S. A., \& Dewey, K. G. (2014). Babies, soft drinks and snacks: A concern in low- and middleincome countries? Maternal \& Child Nutrition, 10(4), 562574. doi: $10.1111 / \mathrm{mcn} .12126$

Lutter, C. K. (2013). The International Code of Marketing of Breast-milk Substitutes: Lessons learned and implications for the regulation of marketing of foods and beverages to children. Public Health Nutrition, 16(10), 1879-1884. doi:10.1017/ S1368980012004235

Maalouf, J., Cogswell, M. E., Bates, M., Yuan, K., Scanlon, K. S., Pehrsson, P., . . Merritt, R. K. (2017). Sodium, sugar, and fat content of complementary infant and toddler foods sold in the United States, 2015. American Journal of Clinical Nutrition, 105(6), 1443-1452. doi:10.3945/ajcn.116.142653

Pereira, C., Ford, R., Feeley, A. B., Sweet, L., Badham, J., \& Zehner, E. (2016). Cross-sectional survey shows that follow-up formula and growing-up milks are labelled similarly to infant formula in four low and middle income countries. Maternal \& Child Nutrition, 12(Suppl. 2), 91-105. doi:10.1111/mcn.12269

Pries, A. M., Huffman, S. L., Mengkheang, K., Kroeun, H., Champeny, M., Roberts, M., \& Zehner, E. (2016). High use of commercial food products among infants and young children and promotions for these products in Cambodia. Maternal \& Child Nutrition, 12(Suppl. 2), 52-63. doi:10.1111/mcn. 12270

Smith, J., \& Blake, M. (2013). Infant food marketing strategies undermine effective regulation of breast-milk substitutes: Trends in print advertising in Australia, 1950-2010. Australian and New Zealand Journal of Public Health, 37(4), 337-344. doi:10.1111/1753-6405.12081

Sobel, H. L., Iellamo, A., Raya, R. R., Padilla, A. A., Olivé, J.-M., $\&$ Nyunt-U, S. (2011). Is unimpeded marketing for breast milk substitutes responsible for the decline in breastfeeding in the Philippines? An exploratory survey and focus group analysis. Social Science \& Medicine, 73(10), 1445-1448. doi:10.1016/j. socscimed.2011.08.029

Sterken, E. (2016, June 29). Protections for breastfeeding at the 69th World Health Assembly [Web log post]. Retrieved from https://actationmatters.org/2016/06/29/protections-for-breastfeeding-at-the-69th-world-health-assembly/

Sweet, L., Jerling, J., \& Van Graan, A. (2013). Field-testing of guidance on the appropriate labelling of processed complementary foods for infants and young children in South Africa. Maternal \& Child Nutrition, 9(Suppl. 1), 12-34. doi:10.1111/ mon.12019

Sweet, L., Pereira, C., Ford, R., Feeley, A. B., Badham, J., Mengkheang, K., . . Z Zehner, E. (2016). Assessment of corporate compliance with guidance and regulations on labels of commercially produced complementary foods sold in Cambodia, Nepal, Senegal and Tanzania. Maternal \& Child Nutrition, 12(Suppl. 2), 106-125. doi: $10.1111 / \mathrm{mcn} .12268$
Theurich, M., \& Grote, V. (2017). Are commercial complementary food distributions to refugees and migrants in Europe conforming to international policies and guidelines on infant and young child feeding in emergencies? Journal of Human Lactation, 33(3), 573-577. doi:10.1177/0890334417707717

Vinje, K. H., Phan, L. T. H., Nguyen, T. T., Henjum, S., Ribe, L. O., \& Mathisen, R. (2017). Media audit reveals inappropriate promotion of products under the scope of the International Code of Marketing of Breast-milk Substitutes in South-East Asia. Public Health Nutrition, 20(8), 1333-1342. doi:10.1017/ S1368980016003591

Walker, R. W., \& Goran, M. I. (2015). Laboratory determined sugar content and composition of commercial infant formulas, baby foods and common grocery items targeted to children. Nutrients, 7(7), 5850-5867. doi:10.3390/nu7075254

Watson, R. (2016). European Parliament rejects high sugar content in baby foods. British Medical Journal, 352, i553. doi:10.1136/ bmj.i553

World Health Organization. (2010). World Health Assembly (WHA) Resolution 63.14 Marketing offood and non-alcoholic beverages to children. Retrieved from http://apps.who.int/gb/ ebwha/pdf_files/WHA63/A63_R14-en.pdf

World Health Organization. (2013a). Information concerning the use and marketing of follow-up formula. Retrieved from http://www.who.int/nutrition/topics/WHO_brief_fufandcode_ post_17July.pdf?ua=1

World Health Organization. (2013b). Scientific and Technical Advisory Group (STAG) on Inappropriate Promotion of Foods for Infants and Young Children. Technical paper on definition of inappropriate promotion of foods for infants and young children. Retrieved from http://www.who.int/nutrition/events/2013 STAG_meeting_24to25June_recommendations.pdf?ua $=1$

World Health Organization. (2016). World Health Assembly (WHA) Resolution 69.9 Ending inappropriate promotion of foods for infants and young children. Retrieved from http://apps.who.int/ gb/ebwha/pdf_files/WHA69/A69_R9-en.pdf

World Health Organization. (2016b). Ending the inappropriate promotion of foods for infants and young children: A primer on WHO guidance. Retrieved from http://iris.wpro.who.int/bitstream/handle/10665.1/13425/WPR_2016_DNH_023_eng.pdf

World Health Organization. (2016c). Report of the Commission on Ending Childhood Obesity. Retrieved from http://www.who. int/end-childhood-obesity/publications/echo-plan-executivesummary/en/

World Health Organization. (2017a). Health Topics: Breastfeeding. Retrieved from http://www.who.int/topics/breastfeeding/en/

World Health Organization. (2017b). The International Code of Marketing of Breast-milk Substitutes: Frequently asked questions (2017 update). Retrieved from http://www.who.int/nutrition/publications/infantfeeding/breastmilk-substitutes-FAQ2017/en/

World Health Organization. (2017c). Tracking progress for breastfeeding policies and programmes: Global breastfeeding scorecard 2017. Retrieved from http://www.who.int/nutrition/ publications/infantfeeding/global-bf-scorecard-2017/en/

World Health Organization, United Nations Children's Fund, \& International Baby Food Action Network. (2016). Marketing of breast-milk substitutes: National implementation of the International Code: Status report 2016. Retrieved from http:// apps.who.int/iris/bitstream/10665/206008/1/9789241565325_ eng.pdf 